\title{
ECTOPARASITAS DE CÃES DOMICILIADOS E ERRANTES DO MUNICÍPIO DE RIO BRANCO-ACRE
}

\author{
Mayara Marques Pereira Fernandes ${ }^{1}$; Francisca Edna Rodrigues Medeiros ${ }^{2}$; Yuri \\ Karaccas de Carvalho ${ }^{3}$; Vânia Maria França Ribeiro ${ }^{3}$; Soraia Figueiredo de Souza ${ }^{3^{\star}}$ \\ ${ }^{1}$ Mestranda, Universidade Federal do Acre, Rio Branco, Acre, Brasil \\ ${ }^{2}$ Médica veterinária autônoma, Rio Branco, Acre, Brasil \\ ${ }^{3}$ Docente do Centro de Ciências Biológicas e da Natureza da Universidade \\ Federal do Acre, Rio Branco, Acre, Brasil \\ Email: soraiasouza@yahoo.com. Autora para correspondência*
}

\section{Recebido em: 22/09/2018 - Aprovado em: 23/11/2018 - Publicado em: 03/12/2018 DOI: 10.18677/EnciBio_2018B38}

\begin{abstract}
RESUMO
Inúmeros estudos relacionados à frequência das infestações por ectoparasitas vêm sendo realizados no Brasil e no mundo, porém não foram encontrados registros no Estado do Acre. Com o objetivo de estudar a epidemiologia das ectoparasitoses em cães domiciliados e errantes da área urbana do município de Rio Branco, Acre, foram coletados, sob inspeção visual, espécimes de ectoparasitas de cães para posterior identificação das espécies. Foram obtidas amostras de 171 animais parasitados, sendo 81 (47\%) domiciliados e 90 (53\%) não domiciliados, e 77 (45\%) machos e 94 (55\%) fêmeas. Quanto às infestações, 124 (73\%) caracterizaram-se como simples e 47 (27\%) como mistas. Foram identificadas sete espécies de ectoparasitas, entre carrapatos, pulgas, piolhos e ácaros causadores de sarna. A infestação por Rhipicephalus sanguineus foi a mais frequente, encontrada em 133 $(77,7 \%)$ animais, seguida por Ctenocephalides felis felis que esteve presente em 50 animais (29\%). Ainda, 20 animais (12\%) apresentaram infestação por Otodectes cynotis, 15 (8,5 \%) por Heterodoxus spinger, cinco (3\%) por Demodex canis e o índice de um $(1,1 \%)$ animal se repetiu tanto para a prevalência de com Sarcoptes scabiei como de Trichodectes canis.
\end{abstract}

PALAVRAS-CHAVE: cães, carrapatos, parasitoses.

\section{ECTOPARASITES OF DOMICILED AND WANDERING DOGS FROM THE CITY OF RIO BRANCO-ACRE}

\begin{abstract}
Numerous studies related to the frequency of the infestations for ectoparasites have been conducted in Brazil and in the world, but no records were found in the State of Acre. With the objective of studying the epidemiology of ectoparasite infestations in domiciled and wandering dogs proceeding from the urban area of the city of Rio Branco, Acre, it were collected specimens of ectoparasites in dogs, under visual inspection, for further identification of the species. Samples were obtained from 171 animals parasitized, being 81 (47\%) domiciled and 90 (53\%) not domiciled, and 77 (45\%) males and 94 (55\%) female. As for the pest infestations, 124 (73\%) were characterized as simple and $47(27 \%)$ as enterprises. It were identified seven species of ectoparasites, between ticks, fleas, lice and mites that cause scabies. The
\end{abstract}


infestation by Rhipicephalus sanguineus was the most frequent, found in 133 (77.7\%), followed by Ctenocephalides felis felis that was present in 50 (29\%) animals. Still, $20(12 \%)$ dogs presented infestation by Otodectes cynotis, $15(8.5 \%)$ by Heterodoxus spinger, five (3\%) by Demodex canis and the index of one $(1.1 \%)$ animal was repeated for both the prevalence of Sarcoptes scabiei and Trichodectes canis.

KEYWORDS: dogs, ticks, parasitic diseases.

\section{INTRODUÇÃO}

As ectoparasitoses em cães (Canis familiaris) são relatadas mundialmente e tem recebido maior enfoque, uma vez que podem trazer danos tanto à vida dos animais, como dos humanos (KOBAYASHI; IWASAKIB, 2017; KARASARTOVA et al., 2018). No Brasil, de acordo com Silva et al. (2014), a erliquiose, babesiose e hepatozoonose caninas são as doenças mais prevalentes em cães transmitidas por carrapatos, mas estes também podem estar relacionados à transmissão de doenças como anaplasmose, borreliose, febre maculosa e leishmaniose (VIEIRA et al., 2013; AKTAS; OZUBEK, 2017; KARASARTOVA et al., 2018).

A superpopulação de animais errantes em área urbana constitui uma fonte de desordens na saúde pública, uma vez que tais animais se encontram expostos a vários tipos de doenças, inclusive de zoonoses, podendo atuar também como sentinelas para infecções em humanos (KAHL, 2018; KARASARTOVA et al., 2018; RECK et al., 2018; WIKEL, 2018). Em estudo realizado em um assentamento rural na região Sul do Brasil, observou-se que de 100 humanos expostos a picadas de carrapatos, cinco apresentaram soropositividade para Erlichia canis e E. chaffeensis (VIEIRA et al., 2013).

Os carrapatos Rhipicephalus sanguineus são os que mais acometem os cães e os mais difundidos mundialmente, seguidos das pulgas Ctenocephalides felis felis (TAYLOR et al., 2017). Os ácaros mais prevalentes em cães são o Sarcoptes scabiei var canis, Otodectes cynotis e Demodex canis (ROCHA et al., 2008). Já entre as espécies de piolhos mais frequentes em cães estão o Trichodectes canis e o Heterodoxus spiniger (RODRIGUES et al., 2001; TAYLOR et al., 2017).

Nesse sentido, a realização de um estudo epidemiológico acerca da frequência de ectoparasitas em cães domiciliados e errantes no município de Rio Branco/AC, constitui a etapa inicial para a elaboração e adoção de medidas adequadas de controle que visem o benefício da saúde animal e, por consequência, da saúde pública, minimizando o risco de exposição da população animal e humana.

\section{MATERIAL E MÉTODOS}

Foram realizadas coletas de ectoparasitas em cães no município de Rio Branco, Acre, no período de agosto de 2014 a fevereiro de 2016, recolhidos e atendidos na Unidade de Ensino e Pesquisa em Medicina Veterinária da Universidade Federal do Acre (UFAC), no Departamento de Controle de Zoonoses (DCZ) e em clínicas veterinárias da cidade.

Para a coleta de pulgas, piolhos e carrapatos, os animais foram adequadamente contidos com auxílio de focinheira e inspecionados manualmente e visualmente. Os espécimes coletados foram acondicionados em frascos com álcool a $70^{\circ} \mathrm{GL}$ e encaminhados ao Laboratório de Análises Clínicas da Unidade de Ensino 
e Pesquisa em Medicina Veterinária/UFAC, para identificação com auxílio de microscópio estereoscópio (lupa) ou microscópio óptico, com aumento de 400x.

Para pesquisa de ácaros, foram confeccionados swabs otológicos e/ou raspados cutâneos, por meio de compressão digital da área lesionada e raspagem com lâmina de bisturi até se iniciar um leve sangramento capilar (LARSON; LUCAS, 2015). O material obtido foi acrescido de óleo mineral e uma lamínula para análise em microscópio óptico com aumento de 40x. Os ácaros, carrapatos, piolhos e pulgas encontrados foram identificados de acordo com as características morfológicas descritas por Taylor et al. (2017). Este estudo foi conduzido sob aprovação do Comitê de Ética no Uso de Animais - CEUA/UFAC (protocolo no 25/2014).

\section{RESULTADOS E DISCUSSÃO}

No período de agosto de 2014 a fevereiro de 2016 foram inspecionados 171 cães que apresentavam ectoparasitas, sendo $81(47 \%)$ deles domiciliados e 90 (53\%) errantes, 77 (45\%) machos e 94 (55\%) fêmeas, 120 (70\%) sem padrão de raça definida e 51 (30\%) com raça definida (Figura 1). Dos 90 animais errantes, apenas um $(1,1 \%)$ apresentou padrão de raça definida, sendo da raça Dachshund e parasitado por $R$. sanguineus.

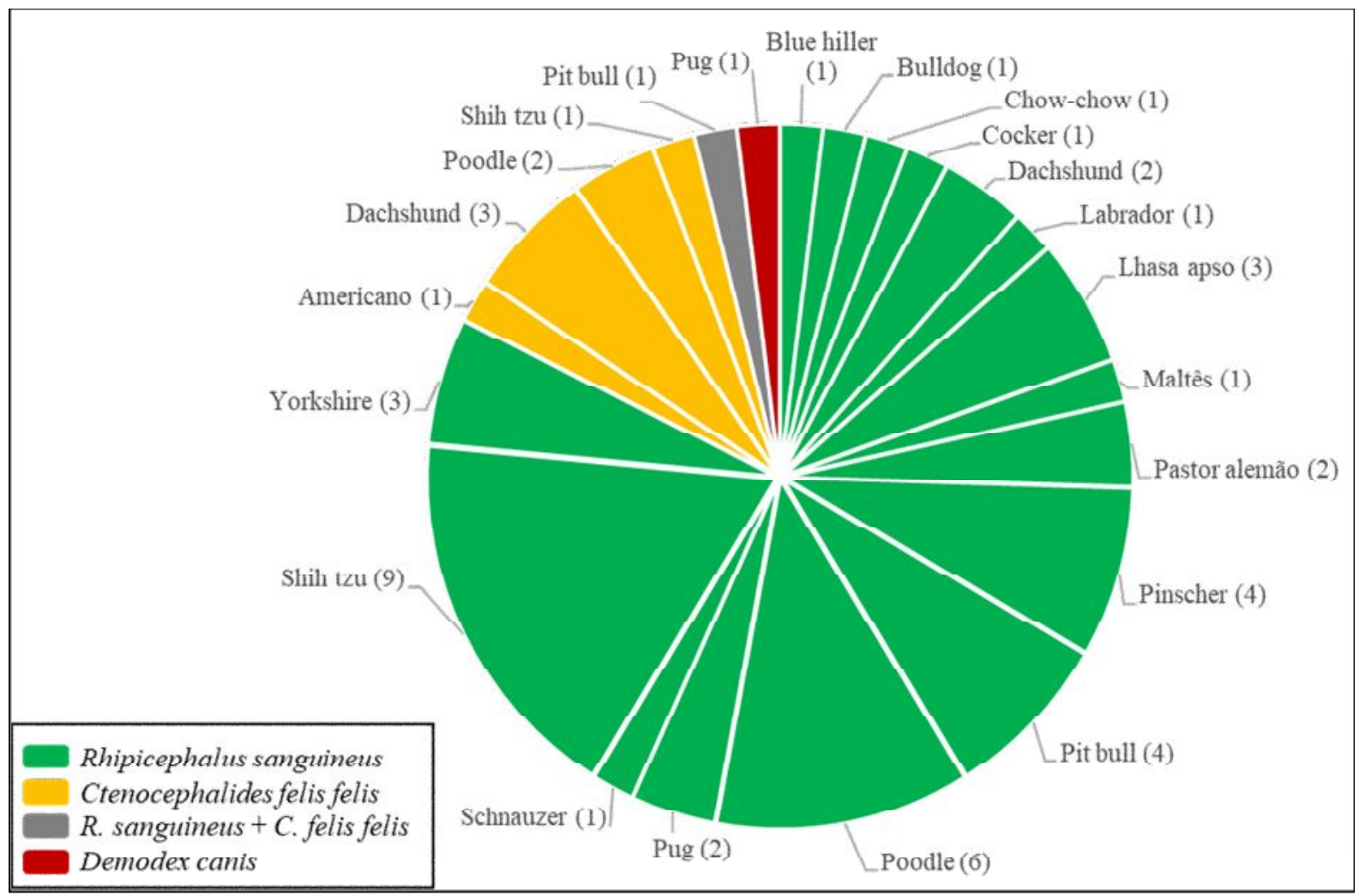

FIGURA 1. Descrição das frequências de ectoparasitas de acordo com a raça de cães domiciliados no município de Rio Branco, Acre.

Foi possível identificar sete espécies de ectoparasitas, entre carrapatos, pulgas, ácaros e piolhos, concordando com a média descrita por Ferreira et al. (2010) de cinco a sete espécies com base em estudos realizados no Brasil acerca da fauna ectoparasitária de cães (RODRIGUES et al., 2001; BELLATO et al., 2003) (Figura 2). 


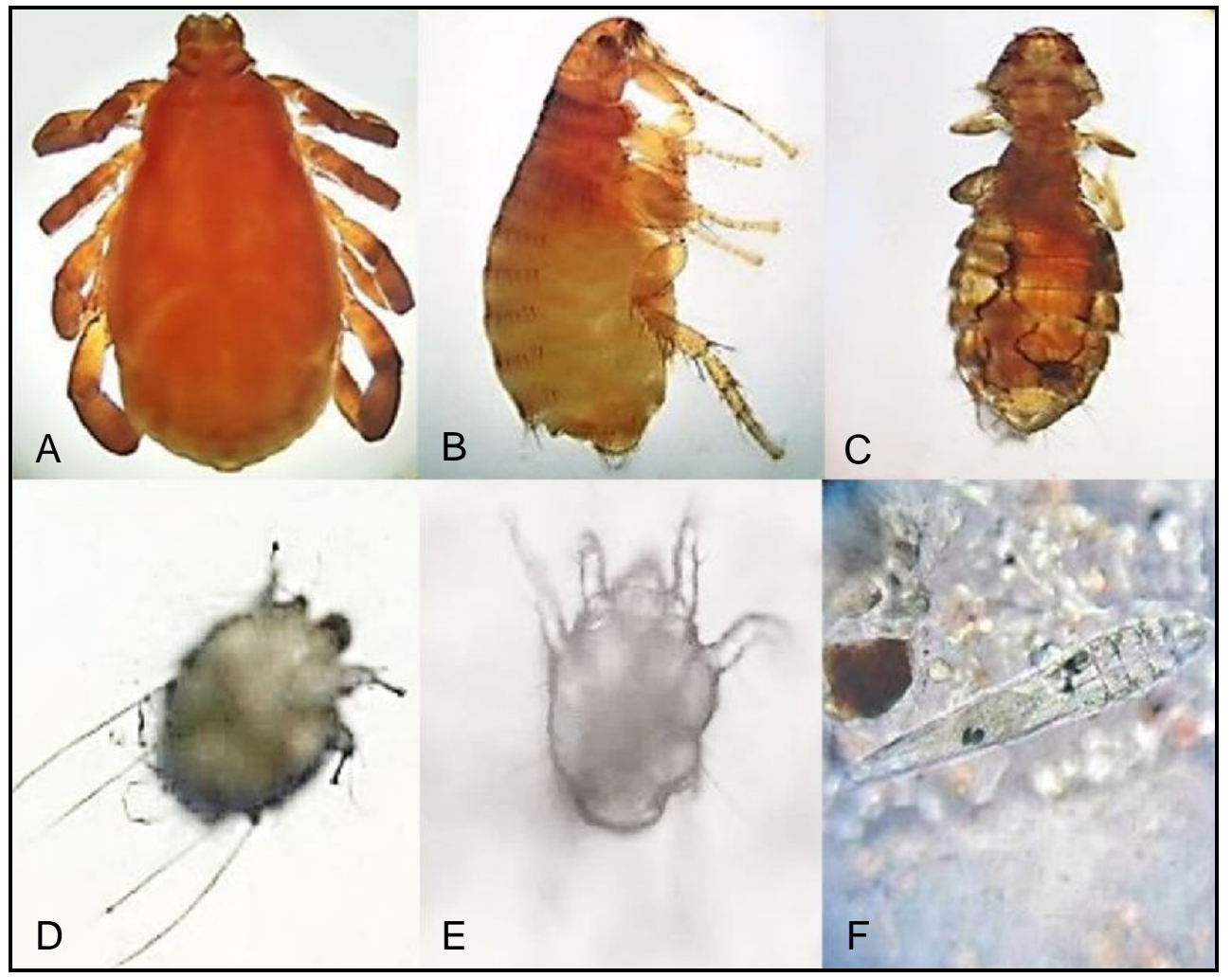

FIGURA 2. Identificação microscópica de ectoparasitas encontrados em cães domiciliados e errantes no município de Rio Branco, Acre. A - Rhipicephalus sanguineus; B - Ctenocephalides felis felis; C - Heterodoxus spiniger, D - Sarcoptes scabiei; E - Otodectes cynotis; F - Demodex canis.

Quanto ao caráter das infestações, a maior prevalência (73\%) correspondeu a infestações únicas (124/171), enquanto que as mistas estiveram presentes em $27 \%$ dos animais (47/171). Ferreira et al. (2010) constataram prevalências semelhantes em cães domiciliados e errantes do município de Apodi/RN, com 73,8\% (62/100) de infestações únicas e 26,2\% (38/100) de infestações mistas, corroborando os resultados obtidos no presente estudo (Tabela 1).

TABELA 1. Descrição das frequências de ectoparasitas em cães domiciliados e errantes no município de Rio Branco, Acre.

\begin{tabular}{ccccccc}
\hline Ectoparasitas & \multicolumn{2}{c}{ Domiciliados } & \multicolumn{2}{c}{ Errantes } & \multicolumn{2}{c}{ Total } \\
\hline $\begin{array}{c}\text { Rhipicephalus } \\
\text { sanguineus }\end{array}$ & 59 & 35 & 33 & 19 & 92 & 54 \\
$\begin{array}{c}\text { Ctenocephalides } \\
\text { felis felis }\end{array}$ & 13 & 8 & 9 & 5 & 22 & 13 \\
$\begin{array}{c}\text { Demodex canis } \\
\text { Heterodoxus } \\
\text { spiniger }\end{array}$ & 1 & 0,5 & 3 & 2 & 4 & 2,5 \\
$\begin{array}{c}\text { Octodectes cynotis } \\
\begin{array}{c}\text { R. sanguineus }+ \\
\text { C. felis felis }\end{array}\end{array}$ & 1 & 0,5 & 3 & 2 & 4 & 2,5 \\
$\begin{array}{c}\text { R. sanguineus } \\
\text { D. canis }\end{array}$ & - & - & 2 & 1 & 2 & 1 \\
\hline
\end{tabular}




\begin{tabular}{|c|c|c|c|c|c|c|}
\hline $\begin{array}{l}\text { R. sanguineus }+ \\
\text { O. cynotis }\end{array}$ & - & - & 10 & 6 & 10 & 6 \\
\hline $\begin{array}{l}\text { R. sanguineus }+ \\
\text { H. spiniger }\end{array}$ & - & - & 6 & 3,5 & 6 & 3,5 \\
\hline $\begin{array}{l}R . \text { sanguineus }+ \\
\text { Trichodectes canis }\end{array}$ & - & - & 1 & 0,5 & 1 & 0,5 \\
\hline $\begin{array}{l}\text { R. sanguineus }+ \\
\text { C. felis felis + } \\
\text { O. cynotis }\end{array}$ & - & - & 4 & 2,5 & 4 & 2,5 \\
\hline $\begin{array}{c}\text { R. sanguineus + } \\
\text { C. felis felis + } \\
\text { H. spiniger }\end{array}$ & - & - & 3 & 1,5 & 3 & 1,5 \\
\hline $\begin{array}{l}\text { C. felis felis + } \\
\text { O. cynotis }\end{array}$ & - & - & 4 & 2,5 & 4 & 2,5 \\
\hline $\begin{array}{l}\text { C. felis felis + } \\
\text { H. spiniger }\end{array}$ & - & - & 1 & 0,5 & 1 & 0,5 \\
\hline $\begin{array}{c}\text { H. spiniger + } \\
\text { Sarcoptes scabiei }\end{array}$ & - & - & 1 & 0,5 & 1 & 0,5 \\
\hline Total & 81 & 47 & 90 & 53 & 171 & 100 \\
\hline
\end{tabular}

n: número absoluto; \%: prevalência.

Entre os animais que apresentaram infestação única, 92 (54\%) estavam parasitados pelo carrapato $R$. sanguineus e $22(13 \%)$ por pulgas $C$. felis felis. $O$ índice de quatro (2,5\%) animais se repetiu tanto para os cães com pediculose por $H$. spiniger, como para os que apresentaram acariose por $D$. canis, e dois (1\%) cães estavam parasitados pelo ácaro 0 . cynotis.

Nas infestações mistas, o ixodídeo $R$. sanguineus esteve presente em sete tipos de associações parasitárias entre 41 (24\%) animais. Quanto a puliciose, 28 (16\%) animais apresentaram infestação por C. felis felis associada a outros ectoparasitos. Ainda, observou-se o índice de um (0,5\%) animal parasitado por $H$. spiniger e $S$. scabiei.

O ectoparasita mais prevalente foi o $R$. sanguineus, presente em $133(77,7 \%)$ cães, sendo esta a única espécie de carrapato encontrada neste estudo, concordando com os resultados obtidos por Soares et al. (2006) e Guimarães et al. (2011) em cães procedentes da área urbana de Juiz de Fora e de Lavras/MG, respectivamente. Silva et al. (2017), por sua vez, constataram em estudo no estado do Paraná que todos os cães infestados por $R$. sanguineus, 23/56 (41\%), provinham de área urbana, mas também observaram a presença de outro ixodídeo, o Ambliomma aureolatum, em 13/56 (23\%) cães da mesma área.

Também se atribuiu ao $R$. sanguineus a maior prevalência das infestações parasitárias em cães domiciliados e errantes de Apodi/RN, contudo, o cão foi caracterizado como hospedeiro acidental de outras duas espécies de carrapatos, cujos hospedeiros primários são equinos e bovinos, devido sua proximidade com as áreas infestadas e grande número e dispersão dos parasitas no ambiente (FERREIRA et al., 2010). Constatação semelhante se deu no estado de Santa Catarina, onde se relatou parasitismo por seis espécies diferentes de ixodídeos em cães domésticos de área urbana e rural (LAVINA et al., 2014). Assim, é possível inferir que os animais amostrados em Rio Branco/AC, principalmente os errantes, não apresentaram significativo contato com demais espécies domésticas ou 
silvestres parasitadas por outros ixodídeos a ponto de carrearem novas espécies para a área urbana em estudo.

O segundo maior índice de infestações foi por pulgas $C$. felis felis, presentes em $50(29 \%)$ animais. Esta foi a única espécie de pulga identificada no presente estudo, assim como observado nos municípios de Juiz de Fora/MG e Mossoró/RN (RODRIGUES et al., 2001; SOARES et al., 2006, FERREIRA et al., 2009), uma vez que esta se trata da espécie mais adaptada ao clima tropical e a mais difundida mundialmente (CASTRO; RAFAEL, 2006; TAYLOR et al., 2017). Bellato et al. (2003) relataram no município de Lages/SC maior prevalência de puliciose, presente em $344 / 714$ (48,18\%) dos cães, e provocada pelas espécies $C$. felis felis, $C$. canis e/ou Pulex irritans, seguida de pediculose por $T$. canis em $34 / 714(5,7 \%)$, não sendo constatada, todavia, a presença de $R$. sanguineus ou $H$. spiniger, apesar da grande quantidade de amostras obtidas, divergindo dos resultados apresentados neste estudo.

Desta forma, os elevados índices de infestação por $R$. sanguineus e $C$. felis felis relacionam-se fortemente ao clima quente e úmido da região, que constituem as condições ideais para estes parasitos (SILVA et al., 2016). Por meio deste estudo, confirma-se a predominância da referida espécie de ixodídeo em cães da área urbana do município de Rio Branco/AC, concordando com estudos similares realizados em demais estados brasileiros (SOARES et al., 2006; GUIMARÃES et al., 2011; SILVA et al., 2017).

Além disso, a maior prevalência de $R$. sanguineus na região de estudo reflete a notável resistência e adaptação desta espécie a diferentes condições climáticas e geográficas, assim como observado por Silva et al. (2016) e Estrada-Peña et al. (2017), que referem a ampla distribuição e predominância de tal espécie em regiões com diferentes características biogeográficas e em diferentes épocas do ano.

De acordo com Souza et al. (2016), o período de dezembro a maio é caracterizado como o dos dois trimestres mais úmidos e chuvosos da região Amazônica. Neste mesmo período realizou-se maior amostragem no DCZ de Rio Branco/AC, em virtude da maior concentração, no referido departamento, de cães provenientes de áreas de alagação no município. Cabe salientar que todos os animais que apresentaram infestação por $O$. cynotis $(20 / 171)$ correspondem a cães recolhidos pelo DCZ, o que se relaciona intimamente com as condições climáticas locais no período de amostragem, superlotação no departamento na época de alagação e confinamento dos animais em canis compartilhados, tendo em vista a grande facilidade de contágio de tal otoacaríase (RODRIGUES et al., 2001).

Neste estudo, todos os animais que apresentaram acariose foram cães errantes, à exceção de um animal domiciliado que apresentou demodicose. As discretas prevalências de acariose por $S$. scabiei, em um $(0,5 \%)$ animal, e por $D$. canis, presente em cinco (3\%) animais, concordam com os baixos índices descritos em estudo similar realizado na Albânia, onde apenas 1/602 (0,2\%) cão domiciliado apresentou demodicose e 4/602 (0,7\%) apresentaram sarna sarcóptica (SHUKULLARI et al., 2016). Todavia, não se descarta a possibilidade de que tais frequências tenham sido mascaradas em função do uso de antiparasitários de amplo espectro como prática rotineira para com os animais recolhidos pelo DCZ em Rio Branco, com o intuito de controlar a incidência de parasitoses entre os animais confinados.

Com relação a prevalência de pediculose, as infestações por $H$. spiniger estiveram presentes em 15 (8,5\%) cães e em apenas um (0,5\%) cão observou-se a presença de $T$. canis. Rodrigues et al. (2001) também relataram a presença de tais 
espécies no município de Juiz de Fora/MG, destacando, contudo, a maior prevalência de $T$. canis, em 15/104 (26,2\%) animais, sobre o $H$. spiniger, em 5/104 (8,33\%). Já em Manaus/AM, Cachoeiro de Itapemirim/ES, Mossoró/RN e em Lages/SC, observou-se o $T$. canis como a única espécie de piolho presente em cães errantes (BELLATO et al., 2003; CASTRO; RAFAEL, 2006; FERREIRA et al., 2009; ALVES et al., 2010).

Em contrapartida, animais domiciliados do município de Lavras/MG não apresentaram piolhos, corroborando os resultados obtidos neste estudo, uma vez que, entre os 81 animais domiciliados amostrados, apenas um $(1,2 \%)$ cão apresentou pediculose, o que pode estar relacionado, então, à dedicação de maiores cuidados por parte dos proprietários aos animais urbanos domiciliados, uma vez que, de acordo com Guimarães et al. (2011), este tipo de parasitismo está associado a certo grau de descuido com os animais.

\section{CONCLUSÃO}

No município de Rio Branco, Acre, predominaram em cães domiciliados e errantes as infestações únicas e mistas por carrapatos $R$. sanguineus e pulgas $C$. felis felis, seguidas por acariose e pediculose causadas por $O$. cynotis e $H$. spiniger, respectivamente. Houve baixa prevalência de demodicose, pediculose por $T$. canis e acariose por S. scabiei.

\section{REFERÊNCIAS}

AKTAS, M; OZUBEK, S. Molecular evidence for trans-stadial transmission of Anaplasma platys by Rhipicephalus sanguineus sensu lato under field conditions. Medical and Veterinary Entomology, v.31, n.3, p.1-6, 2017. Disponível em: <https://bit.ly/2DkNFDu>; DOI: 10.1111/mve.12261.

ALVES, D.P.; CARNEIRO, M.B; DIAS, J.D.; MARTINS, I.V. Ocorrência de parasitos de cães recolhidos pelo Centro de Controle de Zoonoses de Cachoeiro de Itapemirim, Estado do Espírito Santo. Revista Brasileira de Medicina Veterinária, v.32, n.2, p. 97-100, 2010. Disponível em: <https://bit.ly/2PYxgGt>.

BELLATO, V.; SARTOR, A.A.; SOUZA, A.P.; RAMOS, B.C. Ectoparasitos em caninos do município de Lages, Santa Catarina, Brasil. Revista Brasileira de Parasitologia Veterinária, v.12, n.3, p.95-98, 2003. Disponível em: $<$ https://bit.ly/2xukVCK>.

CASTRO, M.C.; RAFAEL, J.A. Ectoparasitas de cães e gatos da cidade de Manaus, Amazonas, Brasil. Acta Amazonica, v.36, n.4, p.535-538, 2006. Disponível em: <https://bit.ly/2OJ71U6>. DOI: 10.1590/S0044-59672006000400015.

ESTRADA-PEÑA, A.; ROURA, X.; SAINZ, A; MIRÓ, G.; SOLANO-GALLEGO, L. Species of ticks and carried pathogens in owned dogs in Spain: Results of a oneyear national survey. Ticks and Tick-borne Diseases, v.8, n.4, p.443-452, 2017. Disponível em: <https://bit.ly/2PRw1Zo>. DOI: 10.1016/j.ttbdis.2017.02.001.

FERREIRA, C.G.; BEZERRA, A.C.; AHID, S.M. Ectoparasitas de cães do Município de Apodi, Rio Grande do Norte, Brasil. Publicações em Medicina Veterinária e Zootecnia, v.4, n.14, p.1-8, 2010. Disponível em: <https://bit.ly/2QQ9Xje>. 
FERREIRA, C.G.; BEZERRA, A.C.; FILGUEIRA, K.D.; FONSECA, Z.A.; AHID, S.M. Levantamento de ectoparasitas de cães e gatos provenientes do município de Mossoró, Rio Grande do Norte, Brasil. Publicações em Medicina Veterinária e Zootecnia, v.3, n.12, p.549-556, 2009. Disponível em: <https://bit.ly/2zn8U3u>.

GUIMARÃES, A.M.; LIMA, B.S.; ROCHA, C.M. Ectofauna parasitária de cães urbanos domiciliados atendidos em clínicas veterinárias particulares na cidade de Lavras, MG. Ciência Animal Brasileira, v.12, n.1, p.172-177, 2011. Disponível em: <https://bit.ly/2xHHtPV>. DOI: 10.5216/cab.v12i1.8485.

$\mathrm{KAHL}$, O. Hard ticks as vectors-some basic issues. Wiener klinische Wochenschrift, v.130, n.15, p.479-483, 2018. Disponível em: <https://bit.ly/2MVcu8r>. DOI: 10.1007/s00508-018-1360-x.

KARASARTOVA, D.; GURESER, A. S.; GOKCE, T.; CELEBI, B.; YAPAR, D. et al. Bacterial and protozoal pathogens found in ticks collected from humans in Corum province of Turkey. PLoS Neglected Tropical Diseases, v.12, n.4, p.1-19, 2018. Disponível em: <https://bit.ly/2NwjGgA>. DOI: 10.1371/journal.pntd.0006395.

KOBAYASHI, A; IWASAKI, H. Human feet bitten by multiple brown dog ticks, Rhipicephalus sanguineus. ID Cases, v.9, n.1, p.8, 2017. Disponível em: <https://bit.ly/2zngB9L>. DOI: 10.1016/j.idcr.2017.04. 007.

LARSON, C.E; LUCAS, R. Tratado de Medicina Externa - Dermatologia Veterinária. São Caetano do Sul: Interbook. 1ed. 2015. 888p.

LAVINA, M.S.; SOUZA, A.P.; BELLATO, V; SARTOR, A.A.; MOURA, A.B. et al. Ixodídeos coletados em equinos e caninos no Estado de Santa Catarina. Revista Brasileira de Medicina Veterinária, v.36, n.1, p.79-84, 2014. Disponível em: $<$ https://bit.ly/2QWd2hQ>.

RECK, J.; SOUZA, U.; SOUZA, G.; KIELING, E.; DALL'AGNOL, B. et al. Records of ticks on humans in Rio Grande do Sul state, Brazil. Ticks and tick-borne diseases, v.9, n.5, p.1296-1301, 2018. Disponível em: <https://bit.ly/2MT3L6Y>. DOI: 10.1016/j.ttbdis.2018.05.010.

ROCHA, G.S.; AHID, S.M.; BEZERRA, A.C.; FILGUEIRA, K.D; SANTOS, J.P. Frequência de ácaros em cães e gatos no município de Mossoró, Rio Grande do Norte. Acta Scientiae Veterinariae, v.36, n.3, p.263-266, 2008. Disponível em: $<$ https://bit.ly/2O0Bolx>.

RODRIGUES, A.F.; DAEMON, E.; D'AGOSTO, M. Investigação sobre alguns ectoparasitos em cães de rua no município de Juiz de Fora, Minas Gerais. Revista Brasileira de Parasitologia Veterinária, v.10, n.1 p.13-19, 2001. Disponível em: $<$ https://bit.ly/2O7jsfc >.

SHUKULLARI, E.; RAPTI, D.; VISSER, M.; PFISTER, K.; REHBEIN, S. Parasites and vector-borne diseases in client-owned dogs in Albania: infestation with arthropod 
ectoparasites. Parasitology Research, v.116, n.1, p. 399-407, 2017. Disponível em: <https://bit.ly/2MQZMrj>. DOI: 10.1007/s00436-016-5302-0.

SILVA, B.R.; GARCIA, M.V.; RODRIGUES, V.S.; ANDREOTTI, R.; DITTRICH, R.L. Ixodidae fauna of domestic dogs in Parana, southern Brazil. Revista Brasileira de Parasitologia Veterinária, v.26, n.3, p.375-377, 2017. Disponível em: <https://bit.ly/2O91OYR>. DOI: 10.1590/S1984-29612017021.

SILVA, M.C.; MUNDIM, A.V.; MENDONÇA, G.A.; MUNDIM, M.J.; GUIMARÃES, E.C. Hemoparasitos em cães domésticos naturalmente infectados, provenientes das zonas urbana e rural do município de Abadia dos Dourados, Minas Gerais, Brasil. Bioscience Journal, v.30, n.5, p.892-900, 2014. Disponível em: <https://bit.ly/2Nx734L>.

SILVA, S.R.; LOURENÇO, E.C.; TASSINARI, W.S.; FAMADAS, K.M. Estudo descritivo da série histórica de ocorrência de carrapatos em cães assistidos em duas unidades privadas de saúde animal na zona oeste da cidade do Rio de Janeiro. Revista Brasileira de Medicina Veterinária, v. 38, supl.3, p.249-259, 2016. Disponível em: <https://bit.ly/2Dknlcw>.

SOARES, A.O.; SOUZA, A.D.; FELICIANO, E.A.; RODRIGUES, A.F.; D'AGOSTO, $M$. et al. Avaliação ectoparasitológica e hemoparasitológica em cães criados em apartamento e casas com quintal na cidade de Juiz de Fora, MG. Revista Brasileira de Parasitologia Veterinária, v.15, n.1, p.13-16, 2006. Disponível em: $<$ https://bit.ly/2pu2cmt>.

SOUZA, E.B.; CARMO, A.M.; MOARES, B.C.; NACIF, A.; FERREIRA, D.B. et al. Sazonalidade da precipitação sobre a Amazônia legal brasileira: clima atual e projeções futuras usando o modelo RegCM4. Revista Brasileira de Climatologia, v.18, n.1, p.293-306, 2016. Disponível em: <https://bit.ly/2O3sc68>. DOI: 10.5380/abclima.v18i0.43711.

TAYLOR, M. A. et al. Parasitologia Veterinária. 4ed. Rio de Janeiro: Guanabara Koogan, 2017. 1052p.

VIEIRA, R.F.; VIEIRA, T.S.; NASCIMENTO, D.A.; MARTINS, T. KRAWCZAK, F.S. et al. Investigação sorológica de espécies de Ehrlichia em cães, equinos e humanos de um assentamento rural do sul do Brasil. Revista do Instituto de Medicina Tropical de São Paulo. v.55, n.5, p.335-340, 2013. Disponível em: <https://bit.ly/2xK5PIC>. DOI: $10.1590 / S 003646652013000500007$.

WIKEL, S. K. Ticks and Tick-Borne Infections: Complex Ecology, Agents, and Host Interactions. Veterinary Sciences, v.5, n.2, p.1-22, 2018. Disponível em: <https://bit.ly/2PXREq>. DOI: 10.3390/vetsci5020060. 